\title{
INTERVIEWING GLOBAL ELITES
}

\author{
William S. Harvey \\ University of Exeter \\ Rennes Drive, \\ Exeter EX4 4PU, UK \\ e-mail: William.Harvey@exeter.ac.uk
}

Citation: Harvey, W.S. (2021). Interviewing Global Elites. In Guttormsen, D.S.A., Lauring, J. and Chapman, M.K. Field Guide to Intercultural Research. Edward Elgar Publishing, Cheltenham, UK.

\begin{abstract}
There has been a sparse literature on interviewing global elites within the field of business and management studies, which is surprising for two reasons. First, there is growing engagement between academics and practitioners in research and teaching. Second, the large volume of researchers who are conducting empirical research on senior managers within a global context. This chapter argues that as a community of scholars we need to provide greater guidance, training and reflection on the practices of interviewing elites. Given the growing importance of engagement and impact for higher education institutions, understanding how to interview elites in a global context will only become more salient over time. This chapter provides an overview of the literature on interviewing elites from across different social science disciplines. Finally, some personal reflections on interviewing elites across various intercultural contexts is provided, with an emphasis on preparing, conducting and concluding elite interviews.
\end{abstract}

Keywords: Interviewing; Global; Elites; Intercultural. 


\section{INTRODUCTION}

Interviewing elites has become an increasingly common methodological practice for many business and management scholars. Although the practice of conducting elite interviews has parallels with interviewing other research subjects, drawing on the literature and my own experiences, it is evident that it also has its own set of challenges. Interviewing elites includes, but is not limited to, interviews with senior managers such as CEOs and Managing Partners, Non-Executive Directors such as Chairs as well as people who hold significant networks of influence and control over the economy and society (Empson, 2018). Khan (2012: 362) argues that elites typically control and have access to resources, which they can convert into other forms of capital, particularly through social capital.

Despite a growing literature on interviewing elites across the social sciences such as political science (e.g. Dexter, 1970, 2006; Goldstein, 2002; Morris, 2009; Richards, 1996), human geography (e.g. Herod, 1999; McDowell, 1998; Parry, 1998; Schoenberger, 1991), sociology (Khan, 2012; Ostrander, 1993) as well as policy (Lancaster, 2017), surprisingly there have been few business and management scholars who have addressed this issue (cf. Empson, 2018; Harvey, 2011; Welch, Marschan-Piekkari, Penttinen, \& Tahvanainen, 2002). This is an oversight because business and management researchers are frequently engaging with elites in different contexts such as research, accreditation, executive education, philanthropic as well as research engagement and impact activity.

Despite the growth of research on elites, there is some evidence that elites are not always impressed by the standards of interviewing conducted by scholars (Empson, 2018; Harvey, 2011), which have implications on future engagement between researchers and elites. This also suggests that as academic scholars we need greater guidance, training and reflection on the practices of interviewing elites. This 
relates to a broader argument around research training that while there is often a lot of classroom-based research training, there is less support at the experiential stages of research (Harvey and Spee, 2019). Furthermore, a recurring theme that emerges from those who have written about interviewing elites is that it is difficult to do effectively because subjects are well-educated, knowledgeable, often guarded and powerful (McDowell, 1998: 2137), which makes the management of interviews challenging. This is not to argue that other forms of interviews are not also challenging in various ways, but to highlight that managing the flow of discussions with elites who are often interviewed in other contexts (e.g. by the media) can present particular difficulties.

There is likely to be a growth of research on elites given the heightened importance that is placed on research engagement and impact by governments (e.g. REF2021, 2019), business school accreditation bodies (e.g. AASCB; EQUIS; AMBA), and within the Academy of Management (e.g. Simsek, Bansal, Shaw, Heugens, \& Smith, 2018). This will necessitate a closer working relationship between researchers and leaders from multiple sectors. Alongside the growing engagement and impact agenda, we are witnessing unprecedented volumes of people moving across international borders for tourism, temporary and permanent business assignments, and global relocation. This suggests that there is the added complexity of where interviewers and interviewees are situated in an increasingly global context. Yet, there is a lack of guidance on conducting research on elites in a global context (see Liu, 2018).

In summary, people in positions of power are often highly aware that their answers in interviews may have wider implications, than just for research, and as such are guarded in their responses, leading to the possibility that the researcher can miss the true, underlying logics or factors under investigation. A researcher may be unaware of the challenges in this kind of research, making the road to valuable 
academic insights all the more arduous. Given the growth in importance of engagement and impact, combined with greater levels of global mobility and interconnectivity, this suggests that understanding how to interview elites in a global context is likely to become increasingly salient. This chapter provides some overview of the literature on interviewing elites as well as some personal reflections on interviewing elites across different intercultural contexts, with a particular focus on preparing, conducting and concluding interviews.

\section{Interviewing elites}

While there has been a proliferation of general guidance on conducting fieldwork, including interviewing (Bryman and Bell, 2011; Kvale, 2008; Silverman, 2013; Saunders, 2017), advice on interviewing elites, such as how we define interviewing elites, gain access to, prepare for and conduct interviews with business elites remains opaque. In terms of conducting interviews, there have been three broad approaches: the neopositivist, the romantic and the localist, which Welch and Piekkari (2006: 420) helpfully summarise (see also Empson, 2018; Alvesson, 2011; Silverman, 1993). The neopositivist approach focuses on extracting accurate information from interviewees in a neutral way. The romantic approach recognises the importance of social interaction to build rapport and encourage open responses from interviewees. The localist approach recognises the interactional nature of interviews and highlights the importance of the social context in which interviews take place.

Drawing on the experiences of scholars in other disciplines, Empson (2018: 65) suggests the romantic approach is a 'far more effective method for obtaining high quality data' compared to the neopositivist approach, but has also found that many elite interviewees have not been overly enamoured by the conduct of interviews by researchers. Herein lies an important challenge around the issue of control 
when interviewing elites because elites tend to have more knowledge, money and status than others (Odendahl and Shaw, 2001) and often receive extensive training from public relations specialists around keeping on message and managing tough questions from journalists and requests from consultants, or clear guidelines from lawyers about keeping silent on certain issues to avoid litigation. Given the different training of elites, this suggests that the context in which an interview is conducted (e.g. the location) could help to overcome some of the invisible barriers (e.g. perceptions around conflicting interests).

There is limited training for researchers collecting data on elites, which is part of a wider problem of a lack of support for researchers at the experiential stage of research (Harvey and Spee, 2019). The lack of practical support for researchers interviewing elites is a major gap in our understanding because power relations manifest in different ways when interviewing elites (Smith, 2006; Conti and O'Neil, 2007; Morris, 2009; Lancaster, 2017).

\section{REFLECTIONS FROM FOUR RESEARCH PROJECTS}

Based on my interviews with more than 400 elite interviewees across five research projects, in the time period 2007-2019, I will now outline some of my reflections, built on my prior reflections as an early career researcher (Harvey, 2010, 2011). These research projects include interviews across over a dozen countries, including Australia, Austria, Bahrain, Canada, China, Germany, Madagascar, the Republic of Congo and the UK. These interviews have been conducted with elites working in a wide range of sectors, including accounting, architecture, banking, consulting, education, engineering, executive search, government, IT and law. 


\section{Preparation for the interview}

Gaining access to elites is often one of the biggest challenges when conducting this sort of research (Goldstein, 2002; Cunliffe and Alcadipani, 2016). We live in an era of unprecedented information which suggests that it is easier than ever before to contact an elite subject through telephone, e-mail, social media, instant messaging as well as of course through face-to-face interaction. At the same time, since there are so many channels of communication, which elites are often expected to engage with, this means that it is difficult to gain their attention because of the very large volume of requests that they receive from a wide group of stakeholders. As a result, if you have a direct connection to or an indirect contact with an elite through a professional or personal network then this is clearly going to significantly increase your opportunity to gain access than contacting them without any prior connection.

When interacting with elites, it is important for them to understand what value is in it for them from your interaction. Most elites are drowning in meetings and appointments so you need to provide a case of why an interview will provide value for them. It is key to explain what the research is about and why it is important. In addition, why do you want to speak to them and what might they benefit from the research. When I was contacting senior partners of Australian executive search firms, I explained to them that they might benefit from the insights of my research through understanding how different leaders were managing their organisational and individual reputations during the global financial crisis (see Harvey, Beaverstock \& Li, 2019). Presumably, the reason why many of these elites were interested in and agreed to participate in the research project was because it was a difficult time for their firms in terms of their financial performance and reputation and they were keen to learn about the approaches of other leaders in a particularly secretive sector. I think my success in gaining access was in part 
because they clearly understood why I wanted to speak to them and what they could benefit from the research.

While the advice to be well prepared before an interview with an elite is a cliché, it is all too easy to forget, as I have myself done on several occasions. This error is especially egregious with elites, as they are often prominent, with a lot of information available in the public domain. This might save you having to ask questions that you already know the answer to, provide a prompt for your discussions during the interview and/or help you to avoid missing some important context. In terms of the latter, when I was conducting interviews in Germany on the reputation of a large global professional service firm, one of the interviewees suggested that I spoke to one of the Partners. During the interview, it was apparent that the interviewee was uncomfortable with some of my questions. It transpired that at the time of the interview, there were major firm-level discussions with another major professional service firm about a merger, which were published in some major business newspapers in Germany and the UK. This was a steep learning curve for me around the importance of keeping in tune with the wider activities of the organisation.

If you are fortunate to gain access to an elite then show flexibility in how, when and where you meet. In terms of how you meet, try to meet in person as this provides greater personal connection than voice over the internet, telephone, personal messaging and other virtual forms of communication. That said, a Skype call or a telephone conversation with an elite is going to provide you with much greater insight into elites than no conversation, so notwithstanding your preferences, do ensure that you provide elites with flexibility. Similarly, in terms of arranging when you meet, remember that however busy you may think you are, your diary is likely to be more flexible than the elite subject's diary. Added to which, 
you may find yourself liaising with his or her executive/personal/private assistant, who will have limited patience with your inflexible diary so try hard to fit around the elite's schedule. Each response from an elite or his/her assistant will have its own unique context and style so think carefully about adopting a heuristic to respond to each situation rather than applying a standardised template (Harvey and Spee, 2019).

The choice of location should strike a balance between a formal and convivial setting, depending on the situation. There is no one-size-fits-all as each interviewer and interviewee will have their own preference. However, despite preferences, strive to avoid settings at either extreme, as it runs the risk of overly formal or informal. For example, when I interviewed a CEO of a major global mining company in London with a colleague, the interview took place in the company's Board Room, where the CEO was flanked on both sides by his deputies on the other side of a long and imposing shiny dark oak table. The setting felt more like litigation than an interview on the topic of how the company managed its reputation in a highly complex environment. This was not a conducive environment for candid responses to interview questions. In contrast, at the request of the interviewee, I conducted an interview over lunch in a public food hall in Vancouver. While the conversation was very convivial, trying to listen to the other person carefully and ask appropriate questions, while eating a bowl of noodles was a disaster! Eating can be good for breaking down barriers, but it is very difficult for conducting an interview because it can rush interviewers with their questions and interviewees with their responses. Restaurants, cafes and food courts also tend to be noisy, which makes recording conversations difficult. In my case, this meant that I had to rely on taking detailed notes, which was not straightforward when combined with asking questions, trying to build rapport with the interviewee and eating a bowl of noodles. Although the above are two extreme examples of formal and informal settings 
for interviews, they demonstrate how the setting of an interview can have significant implications in terms of what interviewees may say and our capacity as researchers to maintain rapport with them and adequately capture the essence of the conversation. In the first example, the cold setting of the interview gave the interview unnecessary formality, which was not relaxing for the interviewers or the interviewees. In the second example, the noise and the eating became a distraction and an impediment to the flow of the interview questions and answers.

\section{Conducting the interview}

As with all types of interviews, interviewing elites takes practice. Introducing an ice breaker at the beginning of the conversation, which may relate to something that you have read about the interviewee or a visual cue as you enter their office, can be helpful for building rapport. Remember to consider their context, namely that they are typically very busy and meet a lot of people. Thus, ensure that you can provide them with a brief overview of the research, why it is important, why you are interested in learning from their insights, how you feel the research might be of benefit to them and how the results from the study will be used. The above is useful for providing some general conversation as well as some context behind your research. At this stage, I would then encourage researchers to cut to the chase and ask interviewees whether they have any questions before commencing, not least because elites are invariably short on time so it is important to maximise the time available.

There has been a lot of work done on power relationships in the interview context. McDowell (1998), for example, has written very candidly about her experiences as a woman interviewing elites in the City of London. Smith (2006) rightly challenges the artificial dualism of interviewing elites versus nonelites, and Cochrane (1998) challenges whether it is even possible to observe power relationships 
through interviews. Rather than rehash best practice and issues related to power relationships when interviewing elites, I encourage reading what other scholars have written previously on the topic (Kezar, 2003; Conti and O’Neill, 2007; Morris, 2009; Harvey, 2011). I have come across power relationships in many guises, leading to impatient, rushed, condescending, patronising, disrespectful, intimidating and reticent discussions. There are many mistakes that I have made as an interviewer and I have no doubt that many interviewees have been unimpressed with my style of interviewing. For example, when I was conducting interviews for my Ph.D research, I was overly focused on the number of interviews so that I could progress from the data collection to the data analysis process, rather than focusing on conducting high quality interviews. While I was successful in conducting over two hundred interviews for my Ph.D research with elites in the pharmaceutical and biotechnology sector around Boston, it had a negative impact on the richness of the data that I collected. Empson (2018) has found through interviewing many professional elites that leaders have often been unimpressed with the conduct and questioning of interviews by academics. This is why it is so important that we share our experiences of interviewing so that we can learn from the practices of others, which can help us to reflect on and improve our interviewing practices in the future (Herod, 1999; Welch et al., 2002; Stephens, 2007; Lancaster, 2017).

Based on my experience, the framing of the interview at the beginning, progressing the questions during the interview while maintaining a natural conversational flow, and providing the opportunity for elites to add any of their own observations and reflections at the end, provide several benefits. First, it enables the interviewer to cover key topics outlined in the research design. Second, it provides the interviewee with an understanding of the context, importance and relevance of the research. Third, it gives sufficient structure and flexibility that leaves the interviewer and interviewee satisfied. Fourth, it provides the 
interviewee with the final word on the subject before the interviewer concludes the interview and thanks the interviewee for his or her time.

Surprisingly, there has been little insights around the challenges of interviewing in an intercultural setting. For example, when I was interviewing the Executive Director of one of the largest logistics companies in the world in Exeter, UK, he told me that he spent over half the days of the year on an aeroplane. This kind of business travel is not exclusive to business elites. For example, the Former Secretary of State, Hilary Clinton, is alleged to have travelled 956,733 air miles in her time in office (The Atlantic, 2013), which is equivalent to flying around the world more than 38 times. This serves to show how much time some elites can spend in different countries, which requires them to be sensitive of working in cultural contexts. This extends to us as researchers conducting interviews and being aware that whether we are travelling to other regions or countries, or not, there is likely to be important cultural considerations. During my interview with the Executive Director, he told me how he spent a lot of his time advising managers and leaders of how to conduct business in different countries because this is what they found most challenging in their work. This has important lessons for researchers because while there is ample general guidance on conducting interviews, the localist approach reminds us of the importance of the localised contact in which we are interviewing (Welch \& Piekkari, 2006; Alvesson, 2011). This requires an understanding of that context and an appropriate tailoring of our approach, which cannot be achieved through a standardised approach (Cassell, Bishop, Symon, Johnson, \& Buehring, 2009).

Having studied, worked, lived and researched in many countries, and having conducted hundreds of interviews in different places, I have found interviewing elites in an intercultural context challenging. 
When I was conducting my Ph.D and postdoctoral research, I found that my age and early career stage was the largest gulf between interviewees and me. This was particularly significant because of my perception of a lack of experience and knowledge in relation to the interviewees, and my perception that interviewees would consider me inexperienced and lacking credibility, which could impact on their willingness to speak to me or provide detailed answers to my questions. I observed less tensions with interviewees because of other social characteristics (e.g. country of origin, skin colour or gender) in relation to mine (e.g. British, white and male). In some cases, these characteristics were not salient either because many interviews were conducted by telephone and therefore some of these social characteristics were less apparent to the interviewee and me, or because they were not a source of tension for both parties in relation to the interview questions. For example, when I was interviewing Partners in executive search firms in Australia and Partners of management consulting firms in France, Germany and China, while I was sensitive around managing my rapport with interviewees and being mindful and respectful of their context (e.g. being competitive during the global financial crisis), I was less aware of the impact of my country of origin, skin colour and gender in these contexts on the research process.

As Herod (1999) observes, the interview process is complex and it can be helpful for researchers to reflect on their 'positionality' in relation to the interviewee. Of course, there are many social and cultural contexts where we may align or misalign, for example in relation to gender, ethnicity, country of origin, class, education, age and career. It is very difficult to know in advance what social and cultural issues will be salient to the interviewer and interviewee during an interview. This means that interviewers need to be flexible in their approach to interacting with interviewees, and mindful of any cues they receive. Herod (1999) rightly challenges the simplistic dualism of researchers being insiders or 
outsiders because it possible to be an insider on one dimension (e.g. ethnicity) and an outsider on another (e.g. education). All of which is to say that there is no single template for conducting interviews with elites because all researchers and elites have their own unique social and cultural characteristics which cannot be easily generalised. However, reflecting on the cultural context that the interviewer and interviewer is coming from, being in tune with any verbal and non-verbal cues that interviewees (and their wider network) give, and being prepared to flex one's approach, can help to provide an environment where interviewees feel able and willing to provide rich responses.

Despite the challenges, as researchers we need to be aware of interviewing in an intercultural environment. Because all researchers and elites have their own distinct cultural footprint, this necessitates that we are in tune with the emotions of others and ourselves, which lies at the heart of emotional intelligence (Salovey and Mayer, 1990). When I was interviewing the senior chief of a tribal region in rural Madagascar, we met in his office, which was a small corrugated iron shed on the edge of the rainforest. We were discussing the challenges that his tribe faced with working with a major mining company around where they could extract minerals from the earth in relation to where members of his tribe were living. At the time of the interview, it was pouring with rain and the noise of rainwater pounding against the corrugated iron roof was deafening. The setting was exacerbated because the research team needed to use a translator, which created an additional layer of complexity for understanding the chief's concerns. At one point, I recall nervously laughing because of the bizarre and awkward setting of the interview for me. This was not an appropriate moment to lose my focus given that we were having a serious discussion about the relationship between a global mining company and members of his local community. What I learned from that experience was despite the extreme setting of the interview, it is important to remain a close rapport with the interviewee. An easier option would 
have been to suggest we speak in the nearby town where it was more sheltered and quieter. Nevertheless, I was aware of the symbolic importance for him of conducting the interview on his turf, not least because of the challenges that he had personally faced in that very area with making decisions on behalf of his community.

\section{Concluding the interview and follow-up}

At the end of the interview, I try to achieve three goals. First, I ask interviewees if there is anything that we have not discussed in our conversation that they would like to share. I find this is an important way of showing them that although I have been asking the questions, they can now ask or tell me something on their terms. Second, I explain what are the next steps with the study and when can they expect to hear more about the results and insights. I always guarantee that I will provide them with an executive summary as well as copies of any published work, if they would like them. Third, I follow-up with interviewees via e-mail to thank them again for their time and insights and provide an approximate timeline for the next steps. I use this as another opportunity to invite them to share any other reflections they have had since we spoke during the interview. If I am looking to speak to other elites then I typically ask them whether they would be willing to put me in contact with other people in their network, according to the selection criteria for interviewees for the research project.

Before the recording device has been switched on at the start of an interview, or after it has been turned off at the end of the interview, can also present additional opportunities to understand the context of the interviewee. This paves the way for some small talk as you are walking with them along the office corridor, in the organisation's premises or in other settings. Because you will typically be walking alongside them and your recording device is switched off, this can be a less confronting time and mean 
that this is an ideal opportunity to build rapport. It may not be appropriate to ask interviewees questions at this point, but it can provide a chance to better understand the context of the interviewee.

Finally, do ensure that before, during and after the interview stages, you show your gratitude for the time that elites have given to conduct the interview. This is clearly common courtesy for all types of interviews and is important for setting the right tone before the interview and may impact on whether they are willing to recommend others to speak with you. At the end of the interview and in my followup interview, I try to solicit some feedback on the interview process because I find that elites are quite straight talking in sharing their impressions of the interview process which can be helpful for reflecting, learning and developing on my future interviewing practices. This can also have an impact on the future practices of my colleagues and students through sharing any significant experiences with them, in a similar vein to what I am seeking to do in this article.

It can take many elite interviews to feel comfortable with the process, and each interview brings a new set of learning. Hence, try to solicit feedback from elites, who will typically be forthright in their views, and embrace your opportunity to learn and develop. Of course, the propensity for people to candidly share their thoughts on the interviewing process may vary according to their culture so soliciting feedback from them directly should be no substitute for being attentive throughout the research process for any verbal and non-verbal cues that they or their colleagues provide.

\section{CONCLUSIONS}

As with all types of interviews, interviewing elites is invariably challenging and never the same from one person to the next. Therefore, in order to continue learning and improving, it is important that as a 
community of scholars we share our experiences with others. We should encourage people at all levels, from within and outside of academia, to share their insights. Like other scholars, while I have gained confidence over time from interviewing several hundred elites across a wide spectrum of sectoral, organisational and intercultural contexts, this does not negate the importance of continually seeking to learn from additional interviews and from others.

I have provided some areas to consider when preparing, conducting and concluding elite interviews. When preparing for the interview, provide some context for the elite subject, think about the right setting for the interview and ensure that you do your background research on the individual and his or her organisation as extensively as possible. When conducting the interview, remind the elite about the research project and explain why you are speaking to them and why the research might be valuable to them. There will always be issues of power relationships and cultural sensitivities to consider and it is important that you are in tune with these and think carefully in real time about how best to navigate them. At the same time, I would also suggest that you do not become distracted by them because you have an important set of issues that you need to discuss in your interview with elites which require your full attention. When concluding the interview, give interviewees the time to provide any additional insights on their own terms. Remember that informal discussions before and after the interview can provide valuable contextual insights and clues which may be less easy to capture during the interview.

Finally, showing gratitude throughout the process is likely to increase your rapport with the interviewee and increase his or her propensity to recommend others to participate in your study. Even though you may have finished your interview with elites, following-up with them and take the time to provide them with insights from your study. This is not only important for giving back to them, it has the additional 
benefit of leaving the door ajar for future correspondence and interaction. A positive engagement with executive/personal/private assistants and other intermediaries is essential in helping to gain and maintain access as well as flexing the diaries of elites to facilitate, lengthen and provide opportunities for follow-up interviews with them. When I was organising a recent meeting and public event with a senior member of the Bank of England, for example, not once was I able to correspond directly with the elite in question, which reinforces the importance of positively engaging with their gatekeepers. 


\section{REFERENCES}

Alvesson, M. 2011. Beyond neopositivists, romantics, and localists: A reflexive approach to interviews in organizational research. Academy of Management Review, 28(1): 13-33.

(The) Atlantic. Hillary Clinton Traveled 956,733 miles during her time as Secretary of State. Url: https://www.theatlantic.com/politics/archive/2013/01/hillary-clinton-traveled-956-733-milesduring-her-time-as-secretary-of-state/272656/; Accessed on 30 January 2020.

Bryman, A. \& Bell, E. 2011. Business Research Methods. (3rd ed.). Oxford: Oxford University Press.

Cassell, C. Bishop, V. Symon, G. Johnson, P. \& Buehring, A. 2009. Learning to be a qualitative management researcher. Management Learning, 40(5): 513-533.

Cochrane, A. 1998. Illusions of power: interviewing local elites. Environment and Planning A, 30(12): 2121-2132.

Conti, J. A. \& O’Neil, M. 2007. Studying power: Qualitative methods and the global elite. Qualitative Research, 7(1): 63-82.

Cunliffe, A. L., \& Alcadipani, R. 2016. The politics of access in fieldwork: Immersion, backstage dramas, and deception. Organizational Research Methods, 19(4): 535-561.

Dexter, L. A. 1970. Elite and specialized interviewing. Evanston, Illinois: Northwestern University Press.

Dexter, L. A. 2006. Elite and specialized interviewing. Colchester, UK: European Consortium for Political Research.

Empson, L. 2018. Elite interviewing in professional organizations. Journal of Professions and Organization, 5(1): 58-69. 
Goldstein, K. 2002. Getting in the door: sampling and completing elite interviews. PS: Political Science and Politics, 35(4): 669-672.

Harvey, W. S. 2010. Methodological approaches for interviewing elites. Geography Compass, 4(3): 193-205.

Harvey, W. S. 2011. Strategies for conducting elite interviews. Qualitative Research, 11(4): 431-441.

Harvey, W.S. \& Spee, A.P. 2019. Gaining and maintaining fieldwork access with management consultants. I Research methods for business students. (8th ed.). Harlow, UK: Pearson.

Harvey, W.S. Beaverstock, J.V. \& Li, H. 2019. Common threats and managing reputation in executive search firms. British Journal of Management. Early View.

Herod, A. 1999. Reflections on interviewing foreign elites: praxis, positionality, validity, and the cult of the insider. Geoforum, 30: 313-327.

Kezar, A. 2003. Transformational elite interviews: Principles and problems. Qualitative Inquiry, 9(3): $395-415$.

Khan, R. S. 2012. The sociology of elites. Annual Review of Sociology, 38: 361-377.

Kvale, S. 2008. Doing interviews. London: Sage Publications Ltd.

Lancaster, K. 2017. Confidentiality, anonymity and power relations in elite interviewing: Conducting qualitative policy research in a politicised domain. International Journal of Social Research Methodology, 20(1): 93-103.

Liu, X. 2018. Interviewing elites: Methodological issues confronting a novice. International Journal of Qualitative Methods, 17: 1-9.

McDowell, L. 1998. Elites in the City of London: Some methodological considerations. Environment and planning $\boldsymbol{A}, 30(12):$ 2133-2146.

Morris, Z. S. 2009. The truth about interviewing elites. Politics, 29(3): 209-217. 
Odendahl, T. \& Shaw, A. M. 2002. Interviewing elites. Handbook of Interview Research. Context \& Method. Thousand Oaks, London: Sage, 299-316.

Ostrander, S. A. 1993. "Surely you're not in this just to be helpful” Access, rapport, and interviews in three studies of elites. Journal of Contemporary Ethnography, 22(1): 7-27.

Parry, B. 1998. Hunting the gene-hunters: the role of hybrid networks, status, and chance in conceptualising and accessing 'corporate elites'. Environment and Planning A, 30: 21472162.

REF2021. Guidance on Submissions. Retrieved from: https://www.ref.ac.uk/media/1092/ref_guidance_on_submissions.pdf; 2019.

Richards, D. 1996. Elite interviewing: approaches and pitfalls. Politics, 16(3): 199-204.

Salovey, P. \& Mayer, J. D. 1990. Emotional intelligence. Imagination, cognition and personality, 9(3): $185-211$.

Saunders, M. Lewis, P. \& Thornhill, A. 2017. Research methods for business students ( $7^{\text {th }}$ ed.)., Harlow, UK: Pearson.

Schoenberger, E. 1991. The Corporate interview as a research method in economic geography. Professional Geographer, 42(2): 180-189.

Silverman, D. 1993. Interpreting qualitative data: Methods for analyzing talk, text and interaction. London: Sage Publications Ltd.

Silverman, D. 2013. Doing qualitative research: A practical handbook. London: Sage Publications Ltd.

Simsek, Z. Bansal, P. Shaw, J. D. Heugens, P. \& Smith, W. K. 2018. From the editors-Seeing practice impact in new ways. Academy of Management Journal, 61(6): 2021-2025.

Smith, K. E. 2006. Problematising power relations in 'elite' interviews. Geoforum, 37(4): 643-653. 
Stephens, N. 2007. Collecting data from elites and ultra elites: telephone and face-to-face interviews with macroeconomists. Qualitative Research, 7(2): 203-216.

Welch, C. Marschan-Piekkari, R. Penttinen, H. \& Tahvanainen, M. 2002. Interviewing elites in international organizations: A balancing act for the researcher. International Business Review, 11(5): 611-628.

Welch, C. \& Piekkari, R. 2006. Crossing language boundaries: Qualitative interviewing in international business. Management International Review, 46(4): 417-437. 